\title{
Research and Innovation Transfer in the Field of PPP Applied to Urban Regeneration Actions and Policies
}

\author{
Carmelina Bevilacqua ${ }^{1, a}$ \\ ${ }^{1}$ Mediterranea University of Reggio Calabria - PAU - Department of Heritage, Architecture, Urban \\ Planning, Via Salita Melissari - 89124, Reggio di Calabria, Italy \\ ${ }^{2}$ cbevilac@unirc.it
}

Keywords: PPPs, Urban Regeneration, NGO, Community Planning, urban clustering.

\begin{abstract}
The European Union has recognized the centrality of community in economic development processes by stressing the role of the cities in delivering smart, sustainable and inclusive growth. The European Commission has recently published a study on how to use European Regional Development Fund (ERDF) to make their cities a better place to live and work [1]. "One of the most engaging results of the study is the variable geometry of strategies in place to achieve urban and territorial cohesion through the implementation of integrated approaches. There are relatively few cases in which the place-based approach was combined with a people-based approach - and even fewer where ERDF and European Social Fund (ESF) cross-funding was developed" [1]. Even the urban dimension in the EU cohesion policy is not a new issue, the way in which the Europe 2020 intends to ensure an integrated approach in the sustainable urban development is quite new because it entails both thematic concentration and the community involvement. According to the Commission's proposals, several ways to support sustainable urban development with the Structural Funds exist: Operational programmes, Integrated Territorial Investment (ITI), Community-Led Local Development (CLLD), Financial Instruments (like Jessica and Jeremie) enhancing new forms of Public Private Partnership. The paper reports some interesting findings of the CLUDs project with respect the role of no-profit organisations in different forms of Public Private Partnerships, used to regenerate urban districts in the Metropolitan Area of Boston (USA). The research funded by IRSES Marie Curie Actions has created an international network of 4 EU universities (Reggio Calabria, Rome, Salford and Helsinki) and 2 US universities (Northeastern University of Boston and San Diego State University) in research and Innovation transfer in the field of PPPs applied to urban regeneration actions and policies.
\end{abstract}

\section{Introduction: Urban Regeneration and Private Public Partnership}

Urban regeneration is a key topic in urban planning, since the great urban renewal and urban regeneration US projects [2] came to fore. In the ' 90 s it massively interested both the Italian planning culture, with the integrated programs experience [3], and the UK context, culminating in the experience of the Social Exclusion Unit [4]. Despite of this continuity, great changes happened in the theoretical background of planning practice in regeneration and its conceptual paradigms evolved by the time. A milestone in turning the deterministic approach mirrored by the models from the ' 60 s into a new one is represented by key-ideas on identity and participation from Jacobs [5] and Davidoff [6].

In the following years, regeneration models based on Public-Private Partnership mechanisms flourished, by emphasising not only the financial opportunities of private investors, but also the further opportunities achievable thanks to a private-led approach. Finally, the institutional theory approach [7] emphasised the importance of involving multiple stakeholders in urban regeneration process, thus merging into the complex concept of sustainability. The 1990s have seen the establishment of public-private partnerships (PPPs) as a key tool of urban regeneration policy [8].

Indeed, the need to attract businesses and industry together with the reduced public resources brought to the implementation of Public Private Partnership to set urban regeneration initiatives. In Europe during "the 1990s urban government faced a movement towards more differentiated forms of governance, and more sectors were getting involved in governing activities and decisions: urban government became urban governance" [9]. This turning point has facilitated the introduction and the 
application of PPP as a tool for urban regeneration. Though, defining PPPs results complicated for several reasons, indeed scholars assign them diverse meaning and connotations. However, it is possible to highlight a set of common features from the existing definitions that identify PPP as: a more or less sustainable cooperation between public and private sectors in which services are developed through risk and cost sharing [10]; as arrangements whereby private parties participate in, or provide support for, the provision of infrastructure and to deliver public infrastructure-based services [11]; as means to achieve a number of public policy actions: to fight against social exclusion, integrating the public and the private components of local communities, voluntary groups; as tools to reform local public services, making them accessible for all; used to improve the quality of the policy making process, through business-community links [12] or to allow a municipality to gain access to specific skills, to create strong competitors to improve antagonism in the local market [9]. Further, not all scholars agree on the positive attitude of partnerships, because of private interests on public issues, decentralisation of governments, separation of responsibility for the purchase of public services from that of their provisions, contracting out public services to the private sector: these actions often confuse the private and public boundaries each other [13]. For Hodge however [14] PPPs have a positive role because they are focused on the benefits of both the private and the public sectors.

Though, "Local strategies differ in their policy composition and institutional configurations, reflecting local circumstances and political choices" [15]. For instance, we found there is a strong difference between the use of PPP in Europe, mainly used for infrastructure realisation, and that one in United States, used also for urban economic and regeneration processes. Originally, in Europe it was mostly a form of privatisation to cope with the lack of public borrowing in providing services and infrastructures. Nowadays we can consider PPPs in Europe in two main different ways: "concession contracts, where the company gets paid by user charges - for example in water services, or toll roads" or "contracts typical of the private finance initiative (PFI) in the UK, where the company gets payments from a public authority" [16]. Moreover, the European Commission suggests a kind of "institutional PPP". By contrast, as concern the urban development processes in USA, "task forces, formal organisations, corporations and even direct subsidies from public entities to private corporations have been described as public-private partnership" [17]. Furthermore, it is useful the distinction between formal and informal partnerships: the first ones, are those based on informal arrangements concerning planning in order to revitalise downtown; belonging to the second ones are partnerships that take place through formal agreements as well as public-private institutions and corporations [18]. Moreover, it can be argued that in USA public and private actors are involved in many ways inside the process and as concern the balance of roles among partners, in PPP public and private parties share costs, revenues and responsibilities [18] and the higher is the sharing the stronger is the partnership [19].

Agreeing on definitions, goals and functions of PPPs broadly recognised, could be a critical aspect on their application, as well for multi-actor and multi-function approaches $[18,19]$.

\begin{tabular}{|c|c|c|c|}
\hline & USA & & Europe \\
\hline Causes & & \multicolumn{2}{|c|}{$\begin{array}{l}\text { Financial crisis in the public sector } \\
\text { Increased mobility of capital } \\
\text { Increased complexity of government tasks } \\
\text { Dominance of neo-liberal ideas }\end{array}$} \\
\hline Autonomy & Privat & UK & Public \\
\hline Bureaucracy & \multicolumn{2}{|c|}{ Fragmented competitive } & Unitary central \\
\hline Public-public relation & \multicolumn{2}{|c|}{ Independent } & Dependent \\
\hline Public-private relation & \multicolumn{2}{|c|}{ Stable } & Weak \\
\hline Leadership & $\begin{array}{l}\text { Strons } \\
\text { busine }\end{array}$ & $\begin{array}{l}\text { ly organized local } \\
\text { ss elite }\end{array}$ & No local business lea \\
\hline
\end{tabular}

Fig. 1: National contexts of public-private partnerships (table1.1) [18]. 
Nevertheless, we can add that, in spite of such differences, a certain degree of flexibility can be traced according to the different shapes that PPPs can assume. The most successful urban regeneration initiative rest on a proper balance between public and private actors, thus, on an effective implementation of PPP instruments. For instance, the differences between USA and EU are particularly strong as concern autonomy, bureaucracy, public-private relations and leadership matters. On the contrary in UK we can observe, a hybrid system: the approach could be considered as point of contact.

\section{A comparative analysis among PPPs in urban regeneration initiatives in the Metropolitan Boston Area.}

The CLUDs research project emphasises the role of the urban district as catalyst of partnership mixed forms' according to an urban spatial configuration. Boston has a strong district configuration as far for urban planning instruments and integrated with economic development strategies. In order to understand what are the key factors of PPP initiatives, 12 case studies were analysed distributed in different districts of the metropolitan area of Boston.

The Metropolitan area of Boston is a region with eighth sub regions, among them the Inner Core Committee (ICC) entails the city of Boston with its neighbourhoods. The Metropolitan Area Planning Council (MAPC) is a regional planning agency serving the 101 cities and towns of the Metropolitan Area of Boston, among the 351 municipalities of the state of Massachusetts. The main topics of MAPC are the promotion of a collaborative regional planning and the implementation of the smart growth principles. MAPC is a public agency created under Massachusetts General Law in the 1963. Boston is a city of distinct neighbourhoods. Each neighbourhood has its own culture, history, architecture, and character. There are 19 neighbourhoods. Boston Urban Planning System is based on a Planning District Rationale. The City Zoning Code establishes (Art. 3) the "Division of City Into Districts". In 1957, the Boston Redevelopment Authority (BRA) was established by the Boston City Council and the Massachusetts Legislature. The BRA assumed the development powers previously held by the Boston Housing Authority and expanded them beyond public housing. In 1960 the City Planning Board was abolished and its powers were transferred to the BRA.

The BRA's statutory authority was set forth in the Massachusetts General Laws, in 1960. Its broad development authorities include the power to buy and sell property, the power to acquire property through eminent domain, and the power to grant tax concession to encourage commercial and residential development. The planning initiatives are divided in the following typologies: Community Planning, Community planning/MA Air Rights, Community planning/economic development; Economic development, Harbour planning, Housing Planning, Industrial Master Plan, Municipal Harbour Planning, Planning Central Artery, Policy planning, Project and implementation plans, public realm planning, transportation planning, Waterfront planning. The BRA's Economic Development Division guides the City's development review process and manages key services and incentives in support of a strong economy for the city of Boston. Working in partnership with neighbourhood residents, business owners, community based organisations, and developers, the Division provides a clear and integrated approach to economic investment that addresses the current and future needs of the city.

\section{Research method and case study analysis}

The methodological approach based on case study analysis has been defined by firstly considering what are the key factors involved in urban regeneration led by local economics that foster Public-Private Partnership initiatives. The aim was to analyse the successful and the unsuccessful factors affecting PPP initiatives in order to accomplish the first objective of the Research concerning: Setting up an analytical process to understand how Public Private Partnership can be both marketable and social sustainable by highlight integrated approach related to Credit access, local resources promotion, job creation, social activation.

The first step concerned the statement of some important assumptions: 
- The use of term "public-private partnerships" in its broadest sense;

- The use the term "local" in its broadest sense

- The main focus that characterise the study of urban management tools in Boston related to: (i) Business Improvement Districts; (ii) Community Development Corporations (iii); Urban-agricultural linkages; (iv) Social enterprises; (v) University-focused; (vi) Non-profit assistance/development; (vii) Business incubators.

The selection of the case studies process started with the construction of a list of potential case studies, located in the Massachusetts area. This list was prepared by local experts and included all the potential cases they considered important the research, i.e. 66 cases covering a broad range for topics and goals. A number of 12 case studies was considered by the research team adequate to investigate the topic, and viable with respect to the available resources. According with the initial statement taken, that is " The use of term public-private partnerships in its broadest sense, the proceeding of the case study analysis led to take the most common definition of Public Private Partnership as "cooperation between the public and private sectors, usually based on formal agreements, sometimes informal as well, to work together towards specific urban development objectives. Public-private partnerships can be understood analogous to business partnerships with profit and risk sharing, general partners and limited partners, and different roles and different objectives for those that are responsible for developing strategies and those responsible for implementing it" [17].

The huge family of approaches in defining Public Private Partnership promoting the economic initiative within urban regeneration process - which represents the main topic of CLUDs project - , has led to distinguish two main categories. The first based on:

a) The initial formal or informal agreement among public and private partners;

b) The involvement of the public sector regarding financing of specific partnership projects and provision of financial or not primarily financial incentives in order to attract private.

c) The dominant thread concerning infrastructure financing, construction, operation, and maintenance

The second based on:

a) A general pursuing to establish a partnership based on community development principles dealing with the involvement of citizens, local companies and professionals to improve various aspects of local communities

b) The legal entity based on non-profit organisation, that allows to participate to a set of advantages, such as tax relieves, special national trust for grant, etc.;

c) The dominant thread concerning in providing services and programs and engage in activities that support communities.

Table1 Boston Metropolitan Area case studies (source: CLUDs scientific report 2012)

\begin{tabular}{|c|c|c|}
\hline Case Studies & Category & Case Studies map \\
\hline $\begin{array}{l}\text { 1. } \text { Boston Marine Industrial Park } \\
\text { 2. Fort Point District } \\
\text { 3. Assembly Square Somerville } \\
\text { 4. } \text { Concord Commons } \\
\text { 5. } \\
\text { Downtown Boston Business Improvement District }\end{array}$ & PPP led & City of BOSTON, \\
\hline $\begin{array}{l}\text { 6. Urban Edge \& Jamaica Plain - Neighbourhood Development } \\
\text { 7. Corporation } \\
\text { 8. Dudley Square Commercial Business District } \\
\text { 9. St. Mark's Area Main Street - Dorchester } \\
\text { 10. Codman Square Neighbourhood Development Corporation } \\
\text { 11. East Boston Main Streets } \\
\text { 12. Dudley Street Neighbourhood Initiative }\end{array}$ & NGO led & \\
\hline
\end{tabular}


Concerning the two above different categories, we can argue that the former considers the definition of PPP in its strictly meaning, the latter in a broader sense. Within the second category, we should pay attention on the difference between the BID instrument and the other instruments based on Neighbourhood/Community Corporation. As matter of fact, the BID is not properly community based, but supported by local business lobbies. The common factor is the institution of a non-profit organisation (NGO). The case studies can be organised on the basis of these two main categories.

The explanatory variables used to build a conceptualisation framework of which factors can be considered as really affected the performance of local initiatives fostered by different forms of PPPs are the followings, articulated in 3 blocks: Socioeconomic Welfare, Housing, Economic Potentials.

- The first block, Socioeconomic welfare (Welfare), comprehends:

Demographic Fragmentation; b) Per Capita Income; c) Level of Education;

- The second block, Housing, comprehends:

a) Housing Unit; b) Vacant Housing Units; c) Owner-occupied Housing Units;

d) Renter-occupied Housing Units; e) For Sale only;

- The third block, Economic Potentials, comprehends:

a) Employees per sector; b) the budget size of the initiative; c) Market property value.

Welfare Block. The block has been investigated to find a synthetic index of welfare by combining Demographic Fragmentation, Per Capita Income, Level of Education, Unemployment. The index of demographic fragmentation is calculated as the complementary index of concentration (Gini index).

High percentage of the demographic fragmentation depicts a high level of distribution of population race in the area. The index related to the per capita income is calculated with respect the Massachusetts total per capita income as baseline 100. The index of education is calculated by considering the highest level reached about bachelor's degree and graduate or professional degree. The index of unemployment is calculated as the percentage of unemployed with respect the total labour force, with additional information about the composition of unemployed - based on the race.

The Welfare block has been correlated with the forms of PPPs for each initiative - case study selected. The aggregate indexes - demographic fragmentation, education, per capita income and unemployment - have been associated to four grade of values - high, medium, medium low, low through cluster analysis technique based on finding similarities between data according to the characteristics found in the data and grouping similar data objects into clusters.

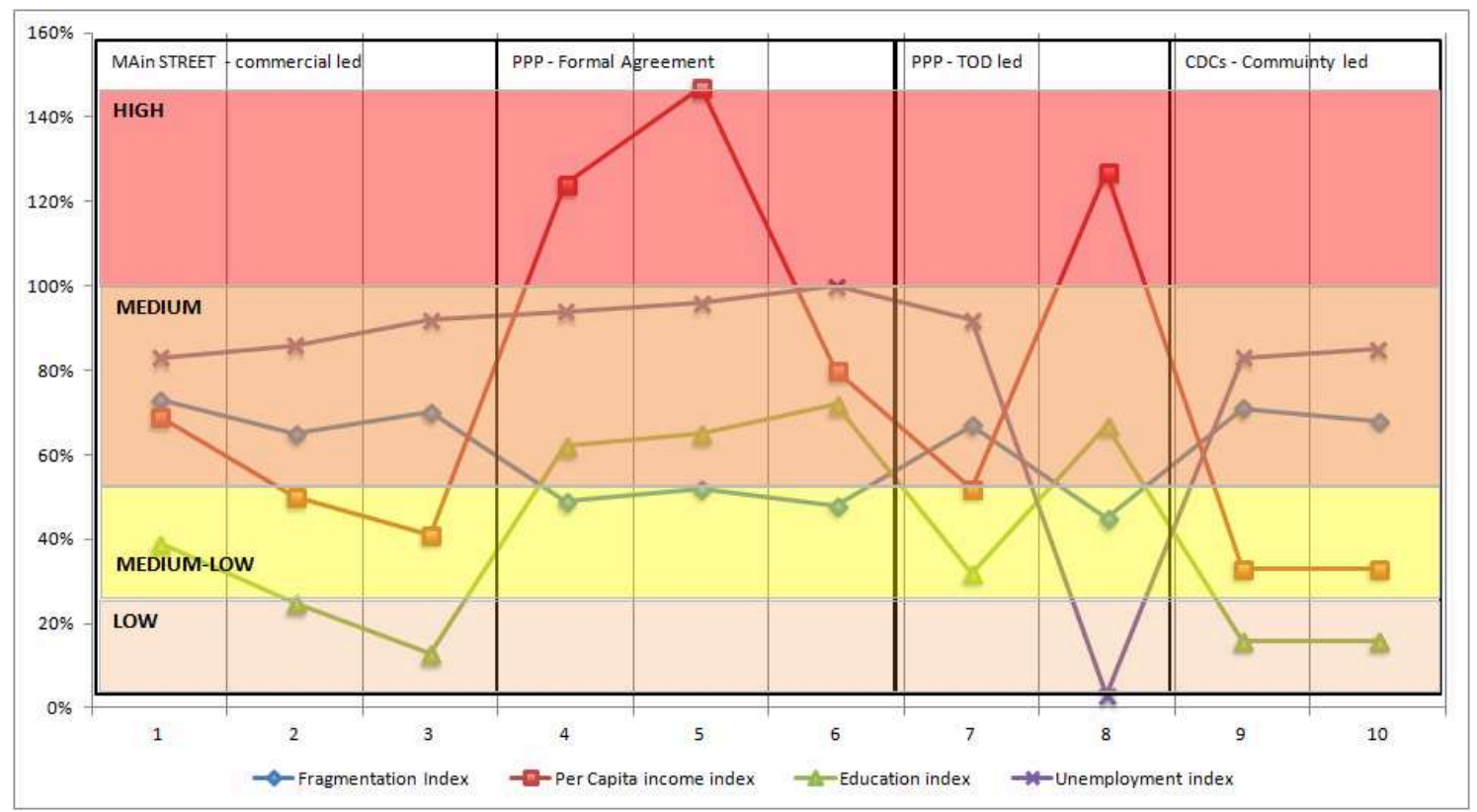

Fig. 2 Cluster Analysis - The Performance of PPP forms with respect to the Welfare Block (Case Study: 1. Washington Gateway Main Street; 2. Mark's Area Main Street; 3. Fort Point District; 4. Dudley Street Neighbourhood; 5. Downtown Boston; 6 Somerville; 7. Boston Marine Industrial Park; 8. East Boston; 9. Dudley Square Commercial Business District; 10.Concord.). 
By dividing the PPP forms into 4 categories (cluster thereby) - Main Street Commercial led, PPP by formal agreement between public and private sectors, PPP fostered by Transfer Oriented Development (TOD) and Community Development Corporations (CDDs) - the level of performance is depicted in the fig. 2.

Housing Block. The block considered the following variables:

1. Housing Units - the percentage increase from 2000 to 2010 ;

2. Vacant Housing Units - the percentage increase from 2000 to 2010;

3. Owner Occupied Housing Units - the percentage increase from 2000 to 2010;

4. Housing for sale only - the percentage increase from 2000 to 2010.

Concerning Housing Block, the cluster analysis led to the following considerations, depicted in the fig. 3.

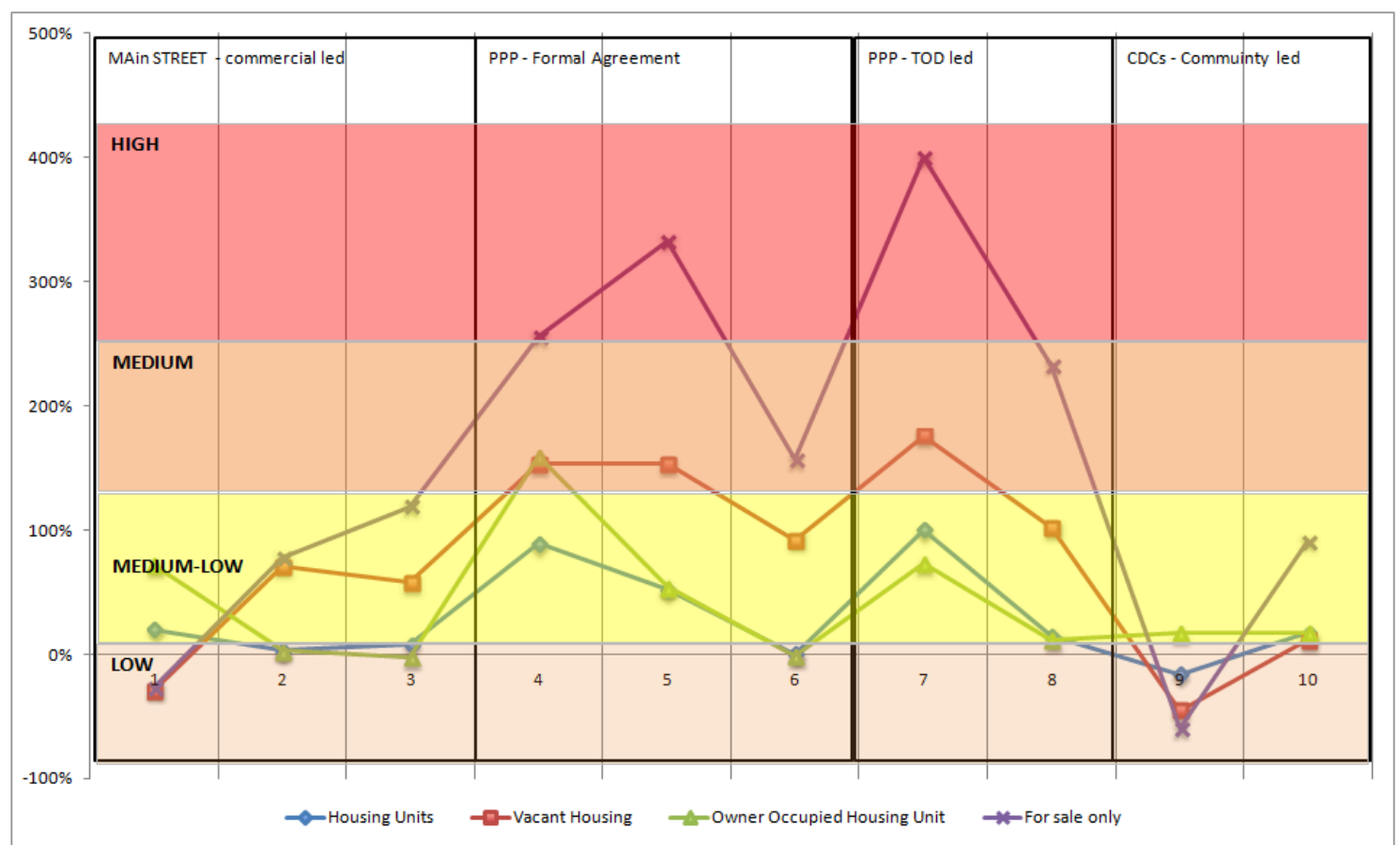

Fig. 3 Cluster Analysis - The performance of PPP forms with respect to the Housing Block (Case Study: 1. Washington Gateway Main Street; 2. Mark's Area Main Street; 3. Fort Point District; 4. Dudley Street Neighbourhood; 5. Downtown Boston; 6 Somerville; 7. Boston Marine Industrial Park; 8. East Boston; 9. Dudley Square Commercial Business District; 10.Concord.).

The PPP formal agreement and PPP TOD led seem mostly affected by the housing block, with a general high level of performance about all representative index of Housing block.

The Main Street and CDCs showed a general low or medium- low performance.

Economic potentials. The block has considered the following variables:

1. Budget size of the initiative for the years 2010, 2011 and 2012;

2. Housing Market Property Value: the sale of housing compared to the prices with respect the percentage of increase during the years 2010, 2011, 2012;

3. Commercial Market Property Value: the sale of commercial compared to the prices with respect the percentage of increase during the years 2010, 2011, 2012;

4. The Employed per sector percentage with respect the years 2000, 2010 and 2011.

The second and third variables have been considered as proxy of the market property value, in terms of how many units and for which price they were sold. Concerning Economic potential block, the cluster analysis led to the following considerations, depicted in the fig. 4.

The PPP TOD led is the only category that reaches high level of performance with respect the employees per sectors. The other categories are on the border of the medium level of performance. 
The commercial profile shows the most irregular performance among all categories, while budget size and housing are more steady among them, between high and medium level of performance.

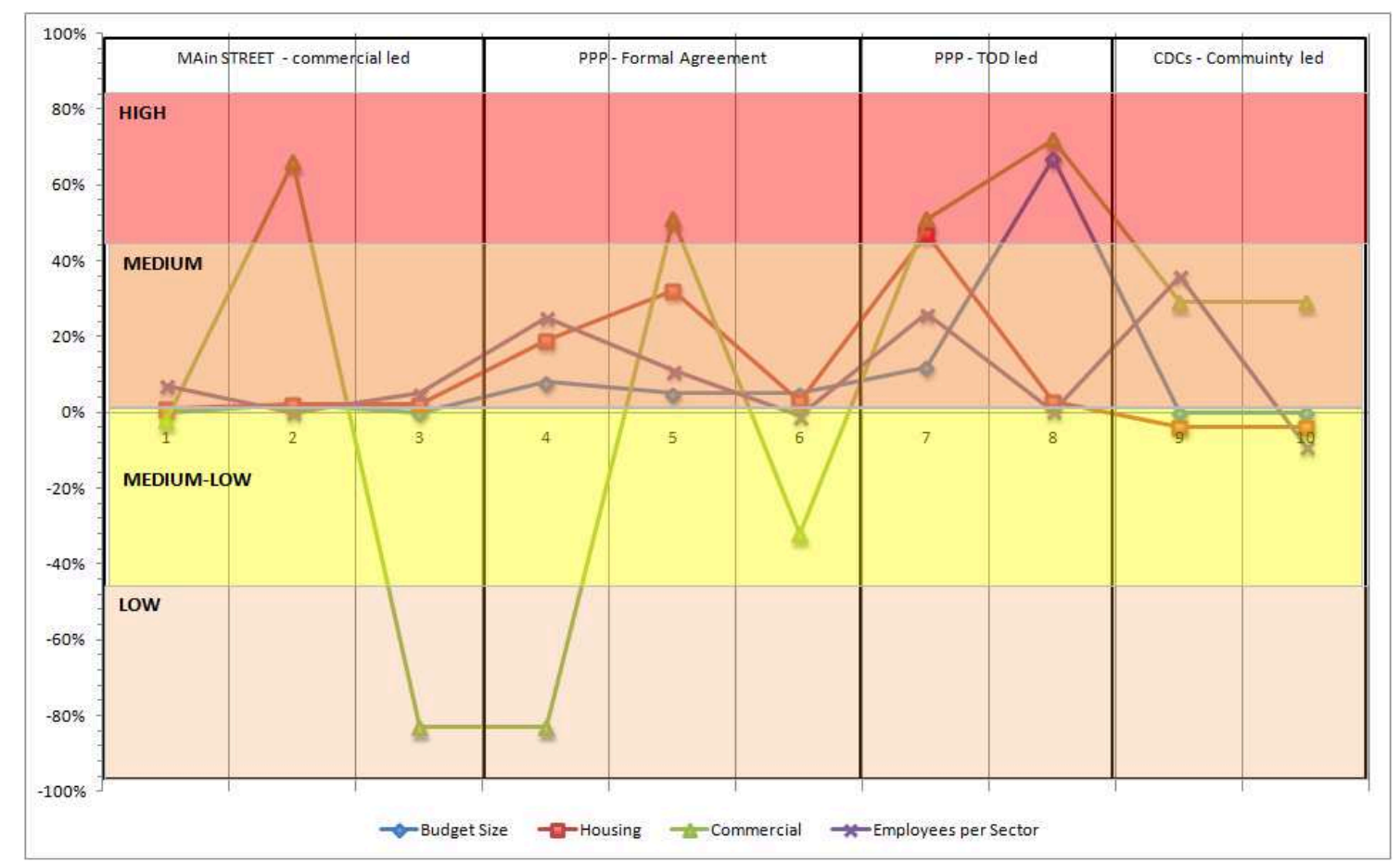

Fig. 4. Cluster Analysis - The performance of PPP forms with respect to Economic Potential Block (Case Study: 1. Washington Gateway Main Street; 2. Mark's Area Main Street; 3. Fort Point District; 4. Dudley Street Neighbourhood; 5. Downtown Boston; 6 Somerville; 7. Boston Marine Industrial Park; 8. East Boston; 9. Dudley Square Commercial Business District; 10.Concord.).

\section{Conclusions: Matrix of correlation - factors of influence to PPPs performance}

In order to understand which factors can affect, either positively or negatively, the four categories of PPP, a matrix of correlation was built.

Through the implementation of a factorial analysis, the results of cluster analysis have been evaluated assigning them a value, within an evaluation range (High, Medium, Medium-Low, Low), and have been correlated to each cluster in terms of performance achieved with respect to each explanatory variable. The correlation matrix shows that the successful or unsuccessful initiatives is based on those factors that can foster or constraint the initiatives themselves.

Table 2 Case studies matrix of correlation

\begin{tabular}{|c|c|c|c|}
\hline Case Study & Positive factors & Constrains & Cluster \\
\hline $\begin{array}{l}\text { Washington Gateway Main Str } \\
\text { Mark's Area Main Street } \\
\text { East Boston }\end{array}$ & High price of commercial & Education & Main Street-Commercial -led \\
\hline $\begin{array}{l}\text { Fort Point District } \\
\text { Downtown Boston } \\
\text { Boston Marine Industrial Park }\end{array}$ & $\begin{array}{c}\text { Housing unit for sale, } \\
\text { Income per capita, } \\
\text { Owner occupied housing units } \\
\text { Budget size }\end{array}$ & Unemployment & PPP - Formal Agreement \\
\hline $\begin{array}{l}\text { Somerville } \\
\text { Concord }\end{array}$ & $\begin{array}{l}\text { Housing unit for sale, } \\
\text { High price of commercial, high } \\
\text { price of house }\end{array}$ & Unemployment & PPP TOD Led \\
\hline $\begin{array}{l}\text { Dudley Street Neighbourhood } \\
\text { Dudley Square Commercial } \\
\text { Business District }\end{array}$ & Medium price of commercial & $\begin{array}{l}\text { Low budget size } \\
\text { Education }\end{array}$ & CDCs \\
\hline
\end{tabular}


The matrix shows how for the first cluster (Main Street-Commercial led) the factor that can foster the success of the initiative is represented by the high price of commercial areas: it means that commercial areas in this cluster are particularly attractive. Conversely, the educational level represents a constraint, e.g. for the lack of cultural initiatives in the area or the low presence of advanced services that require specialised labour force.

The second cluster, that groups initiatives based on PPP with a formal agreement, presents as positive factors: the presence of high number of units for sale, the per capita income, the owner occupied housing units and the budget size. It means that the initiatives belonging to this cluster are really attractive for the real estate and that the high budget size of initiatives is key factor for their success. Here unemployment is considered a constraint due to the fact that job creation refers mainly to white collar jobs, and achievement of mixed-social income is not enhanced to favour weak social categories.

The PPP-TOD led cluster presents some similarities with the previous one. The success of these initiatives relies on the attractiveness of commercial and residential areas. Its main constraint is the unemployment considered in the long-term period. As a matter of fact, the current employment is linked just to temporary works.

The last cluster reported in the matrix (CDCs) shows how the medium price of commercial is a positive factor that affects the performance of PPP, but at the same time the small dimension and the budget of initiatives, and also the lack of proper educational programs that might empower local communities, represent constraints for their effective success.

The distinction between PPP led and NGO led could represent a driver to better understand which could be the model more suitable for Commercial Local Urban District connected with local production. In a very general way, we can argue that, in Europe, the NGO (no profit organisation) seems to play a role more connected with social purposes (see for example the programs under structural funds), while the PPP, in its strictly meaning, plays the main role in urban regeneration process as driver to enhance competiveness. In Europe, Non-profit organisations aim to serve public or mutual benefit other than the accumulation of profits for investors or owners. They provide programmes and services to the community in an attempt to improve social conditions. Many of them are membership organisations dedicated to specific types of activities or action. Their areas of interest include different fields such as promoting arts, culture, humanities, education, protection of the environment, health, social services, disaster relief or international and foreign affairs. They draw public attention to many social issues.

In other words, NGO more direct to convergence policy, PPP more direct to competitiveness policy.

Based on the case study analysis, we can argue that in USA both instruments (PPP and NGO) play a role to enhance competitiveness, the difference is based on community/business led and infrastructure led.

\section{Acknowledgements}

The 7th European Research Framework - Marie Curie IRSES actions granted the CLUDs project.

\section{References}

[1] European Commission, Directorate General for Regional and Urban Policy, Urban Development In The EU: 50 Projects Supported By The European Regional Development Fund During The 2007-13 period, European Union press (2013)

[2] F. Wagner, T. Joder., A. Mumphrey, K. Akundi and A. Artibise (eds): Revitalizing the City, Sharpe, New York (2005)

[3] M. Ricci, P. Avarello: Dai programmi complessi alle politiche integrate di sviluppo urbano, INU, Roma (2000) 
[4] S. Tiesdell, P. Allmendinger: Neighbourhood Regeneration and New Labour's Third Way, Environment and Planning C: Government and Policy, Vol. 19 (2001), pp. 903-926

[5] J. Jacobs: The Death and Life of Great American Cities, Random House, New York (1961)

[6] P. Davidoff: Advocacy and Pluralism in Planning, Journal of the American Institute of Planners, 31, 4, November (1965)

[7] P. Healey: Urban complexity and spatial strategies: towards a relational strategies for our times, Routledge, London (2007)

[8] S. P. Osborne: Public-Private Partnerships: Theory and practice an international perspective, Routledge, (2000)

[9] B. Van Boxmeer, E. Van Beckhoven: Public-Private Partnership in Urban Regeneration: A Comparison of Dutch and Spanish PPPs, European Journal of Housing Policy, Vol. 5 (2005), No. 1, pp. 1-16

[10]E. H. Klijn, G. R. Teisman: Institutional and Strategic Barriers to Public-Private Partnership: An Analysis of Dutch Cases, British Academy of Management Conference 2002, 9-11, London, Middlesex University (2002)

[11]D. Grimsey, M. Lewis: Public Private Partnerships: The worldwide revolution in infrastructure provision and project finance, Edward Elgar Publishing (2007)

[12] S. O. Collin: In the Twilight Zone: A Survey of Public-Private Partnerships in Sweden, Public Productivity \& Management Review, Vol. 21 (1998), No. 3, pp. 272-28

[13]A. Turhani, G. Shquau: Public-Private Partnerships For and Against, China-USA Business Review, Vol. 10 (2011), No. 9, pp. 893-898

[14]G. A. Hodge, C. Greve: PPPs The passage of time permits a sober reflection, Journal compilation Institute of Economic Affairs Published by Blackwell Publishing, Oxford, pp. 33-39 (2009)

[15]I. Turok: Property-led urban regeneration: panacea or placebo?, Environment and Planning A, Vol. 24(1992), No. 3, pp.361-379

[16]D. Hall: PPPs in the EU, Services International Research Unit (PSIRU), Business School, University of Greenwich, (2008)

[17]D. Reuschke: Public-Private Partnerships in Urban Development in the United States, NEURUS- Network of European and US Regional and Urban Studies, (2007)

[18]M. Bult-Spiering: Strategic Issues in Public Private Partnerships. An alternative perspective. Blackwell Publishing (2006)

[19]Lyall, 1982: p.52 in Public-Private Partnerships in Urban Development in the United States. D. Reuschke NEURUS- Network of European and US Regional and Urban Studies (2001) 